\title{
Neutronics and Activation Analysis of Lithium-based Ternary Alloys in IFE Blankets
}

\author{
Alejandra Jolodosky ${ }^{\mathrm{a}}$, Kevin Kramer ${ }^{\mathrm{c}}$, Wayne Meier ${ }^{\mathrm{b}}$, James DeMuth ${ }^{\mathrm{b}}$, Susana Reyes ${ }^{\mathrm{b}},{ }_{\text {Massimiliano }}$ \\ Fratoni $^{\mathrm{a}}$ \\ ${ }^{a}$ University of California, Berkeley, Berkeley, CA 94706 aleja311@berkeley.edu \\ ${ }^{b}$ TerraPower, Bellevue, WA98005 \\ ${ }^{c}$ Lawrence Livermore National Laboratory, P.O. Box 808 Livermore, CA
}

\begin{abstract}
An attractive feature of using liquid lithium as the breeder and coolant in fusion blankets is that it has very high tritium solubility and results in very low levels of tritium permeation throughout the facility infrastructure. However, lithium metal vigorously reacts with air and water and presents plant safety concerns. The Lawrence Livermore National Laboratory is carrying an effort to develop a lithium-based ternary alloy that maintains the beneficial properties of lithium (e.g. high tritium breeding and solubility) and at the same time reduces overall flammability concerns. This study evaluates the neutronics performance of lithium-based alloys in the blanket of an inertial fusion energy chamber in order to inform such development. 3-D Monte Carlo calculations were performed to evaluate two main neutronics performance parameters for the blanket: tritium breeding ratio (TBR), and the fusion energy multiplication factor $(E M F)$. It was found that elements that exhibit low absorption cross sections and higher $q$-values such as $\mathrm{Pb}, \mathrm{Sn}$, and $\mathrm{Sr}$, perform well with those that have high neutron multiplication such as $\mathrm{Pb}$ and Bi. These elements meet TBR constrains ranging from 1.02 to 1.1. However, most alloys do not reach EMFs greater than 1.15. Additionally, it was found that enriching lithium with ${ }^{6} L i$ significantly increases the TBR and decreases the minimum lithium concentration by more than 60\%. The amount of enrichment depends on how much total lithium is in the alloy to begin with. Alloys that performed well in the TBR and EMF calculations were considered for activation analysis. Activation simulations were executed with 50 years of irradiation and 300 years of cooling. It was discovered that bismuth is a poor choice due to achieving the highest decay heat, contact dose rates, and accident doses. In addition, it does not meet the waste disposal ratings (WDR). Some of the activation results for alloys with Sn, Zn, and Ga were in the higher end and should be considered secondary to elements such as Sr and $B a$ that had overall better results. The results of this study along with other considerations such as thermodynamics, and chemical reactivity will help down select a preferred lithium ternary alloy.
\end{abstract}

Keywords IFE, ternary, TBR, EMF, enrichment, activation

\section{Highlights}

- Monte Carlo calculations were performed on numerous lithium ternary alloys

- Elements with high neutron multiplication performed well with low absorbers

- Enriching lithium decreases minimum lithium concentration of alloys by $60 \%$ or more

- Alloys that performed well neutronically were selected for activation calculations

- Alloys activated, except LiBaBi, do not pose major environmental or safety concerns

\section{Introduction}

Lithium is often the preferred choice as breeder and coolant in fusion blankets as it offers excellent heat transfer and corrosion properties, and most importantly, it has a very high tritium solubility and results in very low levels of tritium permeation throughout the facility infrastructure [1]. However, lithium metal vigorously reacts with air and water and exacerbates plant safety concerns [2]. For this reason, over the years, numerous blanket concepts have been proposed with the scope of reducing concerns associated with lithium [3-4]. The European helium cooled pebble bed breeding blanket (HCPB) physically confines lithium within ceramic pebbles [3]. The pebbles reside within a low activation martensitic ferritic steel structure and are cooled by helium. The blanket is composed of the tritium breeding lithium ceramic pebbles and neutron multiplying beryllium pebbles. Similar concepts are being investigated in China, Korea, and India [5-8], while Japan is exploring a ceramic breeder cooled by pressurized 
water [9]. Other blanket designs utilize lead to lower chemical reactivity [10]; LiPb alone can serve as a breeder, coolant, neutron multiplier, and tritium carrier. India is taking advantage of this with its Lead-Lithium cooled Ceramic Breeder (LLCB) design. Europe is developing a He cooled lithium lead (HCLL) blanket which utilizes helium as the coolant and lithium-lead as the breeder, with reduced activation ferritic-martensitic steel (RAFM) as the structural material [11]. The US is also utilizing $\mathrm{LiPb}$ in their blanket design with the dual-coolant lead-lithium concept (DCLL); helium is used to cool the first wall and structural components made up of low-activation ferritic steel, whereas lithium-lead ( $\mathrm{LiPb})$ acts as a self-cooled breeder in the inner channels of the blanket [3]. The heliumcooled steel and lead-lithium alloy are separated by silicon carbide flow channel inserts which thermally insulate the self-cooled breeder region from the helium cooled steel walls. This creates a LiPb breeder with a much higher exit temperature than the steel which increases the power cycle efficiency and also lowers the magnetohydrodynamic (MHD) pressure drop [12]. Additionally, it produces low afterheat and low operation pressures [3]. China is designing a dual functional lithium-lead (DFLL) test blanket module (TBR) which allows both a helium-cooled quasi-static lithium-lead (SLL) concept and a He/PbLi dual-cooled lithium-lead (DLL) concept to be tested [13-14]. Molten salt blankets with a mixture of lithium, beryllium, and fluorides (FLiBe) offer good tritium breeding, low electrical conductivity and therefore low MHD pressure drop, low chemical reactivity, and extremely low tritium inventory [3]; the addition of sodium (FLiNaBe) has been considered because it retains the properties of FliBe but also lowers the melting point [4]. One of the most recent designs is the Korean He-cooled molten lithium (HCLM) blanket with ferritic steel as a structural material [15]. Although many of these blanket concepts are promising, challenges still remain. The limited amount of beryllium available poses a problem for ceramic breeders such as the HCPB. Additionally, ceramic breeders require high porosity in the pebbles to allow tritium to be extracted, significantly reducing the thermal conductivity [16]. FLiBe and FLiNaBe are highly viscous and have a low thermal conductivity [3]. Corrosion issues occur between lithium-lead blankets and the steel constituents from structural materials. This negatively impacts the structural integrity of the blanket structures due to wall thinning and transport of corrosion products throughout the liquid metal loop. An important common issue found in all three blanket technologies is tritium permeation. Tritium has a high partial pressure in each of the blankets and thus, low solubility. Tritium then permeates into structural material, heat exchanger, first wall, and containment structure potentially releasing into the environment and posing a high safety concern [16]. Lawrence Livermore National Laboratory (LLNL) decided to combat many of the issues found with the blanket concepts by attempting to develop a new lithium-based alloy — most likely a ternary alloy — which maintains the beneficial properties of lithium (e.g. high tritium breeding and solubility) while reducing overall flammability concerns for use in the blanket of an Inertial Fusion Energy (IFE) power plant [17-18]. The IFE engine employs inertial confinement fusion (ICF) through the use of lasers aimed at an indirect-driven target composed of deuterium-tritium fuel. The fusion driver/target design implements the same physics currently experimented at the National Ignition Facility (NIF). The IFE reactor uses lithium in both the primary coolant and breeder; therefore, lithium-related hazards are of primary concern. Although reducing chemical reactivity is the primary motivation for the development of new lithium alloys, the successful candidates will have to guarantee acceptable performance in all their functions. The scope of this study is to evaluate the neutronics performance of a large number of lithium-based alloys in the blanket of a fusion reactor. In particular, parameters are set on the tritium breeding ratio (TBR) [19] and energy multiplication factor (EMF) [20] which allow candidate alloys to be selected. Activation analysis is then utilized on the selected alloys to assess specific safety and environmental properties. This manuscript is organized as follows: Section 2 presents the models and methodologies used for the analysis; Section 3 discusses the results; Section 4 summarizes findings and future work.

\section{Models and Methodology}

\subsection{Chamber Model}

The neutronics performance of each alloy was evaluated in the blanket of the IFE power plant. The blanket is built around the fusion chamber that consists of a central spherical cavity with a $13.004 \mathrm{~m}$ radius. Fusion occurs at the center of the void chamber where the laser beams impact the fuel target. The ICF target releases $132 \mathrm{MJ}$ from $\mathrm{D}(\mathrm{T}, \mathrm{n}) \alpha$ reactions; $97.45 \mathrm{MJ}$ is in neutrons kinetic energy and 34.55 MJ is in X-rays and ions [21]. The target also releases $4.69 \cdot 10^{19}$ neutrons from fusion and additional $0.13 \cdot 10^{19}$ neutrons $(2.8 \%$ of the total) from $(\mathrm{n}, 2 \mathrm{n})$ reactions 
with the compressed DT fuel and the lead hohlraum. Alpha particles instantly deposit their energy in the surrounding DT fuel, in the ablator materials, and in the lead capsule resulting in the release of X-rays and ions [22]. Xenon fills the void chamber at a density of $6 \mu \mathrm{g} / \mathrm{cm}^{3}$ and shields the chamber wall (first wall) from ions and X-rays [21]. The blanket surrounds the central chamber and consists of a series of coolant/breeder layers separated by structural components (Table 1). The structural material is HT9 (composed of iron (85.9\%), chromium (12.1\%), and the rest is carbon, silicon niobium, molybdenum, and tungsten with density of $8 \mathrm{~g} / \mathrm{cm}^{3}$ ); it features high resistance against radiation damage and low chemical reactivity. In the original design, the coolant/breeder material is lithium; this study replaces lithium with a ternary lithium alloy. The blanket is completed by a $100 \mathrm{~cm}$ graphite reflector $\left(1.7 \mathrm{~g} / \mathrm{cm}^{3}\right)$. The LIFE plant is assumed to generate 2,200 MW of fusion power.

Table 1 Composition and dimensions of the blanket component
\begin{tabular}{|r|c|c|}
\hline Layer, \# & Material & $\begin{array}{l}\text { Thickness } \\
(\mathbf{c m})\end{array}$ \\
\hline 1 & HT9 & 0.5 \\
2 & Breeder/Coolant & 1 \\
3 & HT9 & 0.5 \\
4 & Breeder/Coolant & 100 \\
5 & HT9 & 0.5 \\
6 & Breeder/Coolant & 50 \\
7 & HT9 & 0.5 \\
8 & Graphite & 100 \\
\hline
\end{tabular}

Neutron and photon transport calculations were performed using the three-dimensional Monte Carlo transport code MCNP6 [23]. A simplified model consisting of concentric spherical regions was assumed (Figure 1). The model also includes 42 penetrations through the blanket representing the beam ports, as well, the target injection port at the top of the chamber and the debris exit port at the bottom. Modeling the indirect-driver and target is extremely complex, and for the scope of this study the DT target was represented as a point source at the center of the chamber with a neutron energy distribution as obtained in accurate target models (Figure 2). The energy spectrum accounts for the scattering of the fusion neutrons with the DT target and lead hohlraum. All materials in the model utilized ENDF/BVII.I cross sections at $900 \mathrm{~K}$ [24].

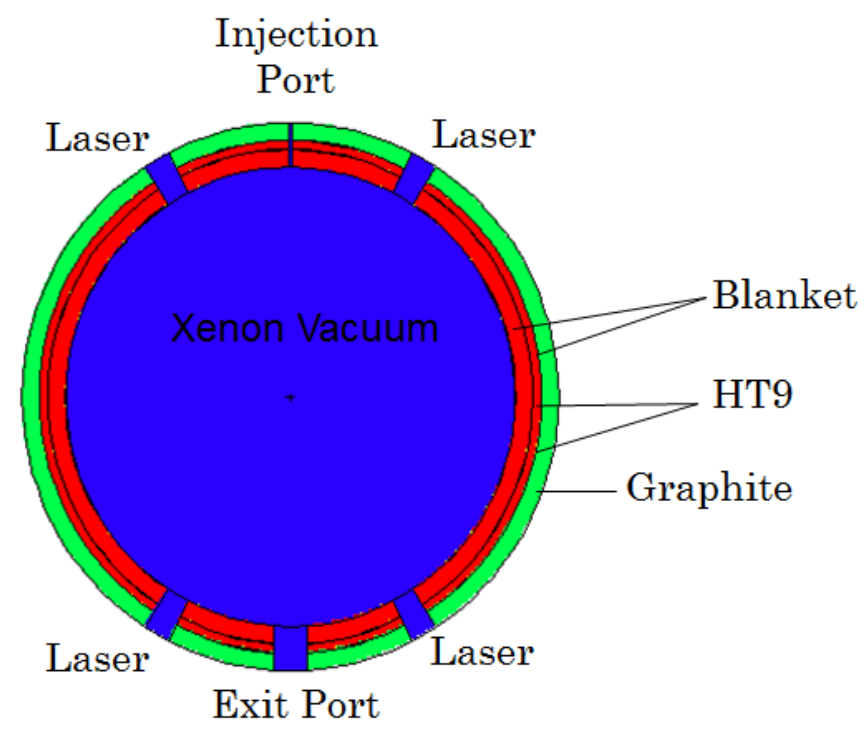


Figure 1: MCNP model of LIFE viewed from the xz plane.

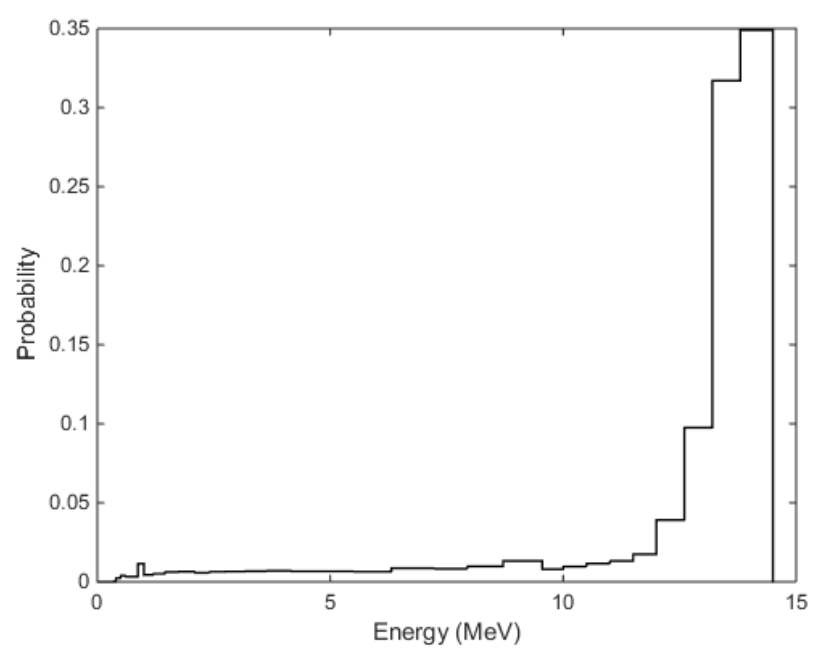

Figure 2: Fusion source neutron energy distribution [25].

The neutronics performance of the alloys was evaluated by the TBR and EMF, as mentioned previously. Tritium production was calculated by utilizing the F4 tally in MCNP [23]. The TBR in this study accounts for losses due to radioactive decay, and only for a limited storage inventory that is needed under emergencies to continue operation [16]. Earlier studies on the IFE design assumed a minimum TBR constrain of 1.02. This is lower than what other fusion plants require due to the high fractional burn-up $(\sim 30 \%)$ in the IFE source and lower tritium permeation in the lithium alloy coolant [26]. Additionally, this study excludes the need to produce a startup inventory for other reactors [16]. The EMF is given by:

$$
E M F=\frac{E_{d}+E_{\alpha}}{E_{f}}
$$

where $E_{d}$ is the total energy deposited in the chamber (first wall, breeding regions, structures, and reflector) and surrounding regions (shield, beam dumps, etc.) as the result of neutron reactions; $\mathrm{E}_{\alpha}$ is the energy of the X-rays and ions (from alpha interactions) absorbed in the chamber gas and subsequently the first wall — this is calculated to be 4.607 MeV; $\mathrm{E}_{\mathrm{f}}$ is the total fusion energy released per D-T reaction $(17.6 \mathrm{MeV})$. The neutron and neutron induced gamma energy deposited in regions outside the chamber is included with the expectation that this power will be recovered and will contribute to the overall power cycle. An EMF of at least 1.1 was chosen to achieve a reasonable cost of electricity.

\subsection{Activation Analysis}

Neutron activation analysis was performed using ACAB [27]. The multigroup activation cross section library is selected from one of the group-wise libraries available in EAF-2007 [28]. The group structure used in this study is VITAMIN-J (175 groups). The decay library was also from EAF-2007. MCNP6 provided the multi-group flux required by $\mathrm{ACAB}$ for collapsing cross sections. Activation analysis was performed for a 2,200 MW plant with an irradiation history of 50 years and cooling time of up to 300 years. One important thing to note is that the total blanket volume includes the $3,478 \mathrm{~m}^{3}$ inside the chamber, and the $940 \mathrm{~m}^{3}$ outside during irradiation. Thus, the alloy is inside the chamber for $79 \%$ of the total residence time. The flux is therefore adjusted by a factor of 0.79 . The results are divided by this factor to account for the entire volume of the blanket. Additionally, it is assumed that feeding additional lithium into the chamber is not necessary due to the small ${ }^{6} \mathrm{Li}$ burn-up (ranging from $2 \%-8 \%$ ) and only $1 \%$ decrease of TBR at end of irradiation. Tritium is assumed to be extracted from the coolant/breeder after irradiation to be reprocessed and reused in the source. All the activation parameters, except for accident dose, are examined after shutdown and thus do not include tritium in the results. An accident is assumed to occur during operation when tritium is still mixed with the rest of the coolant/breeder. 


\subsection{Safety and Environmental Parameters}

Data from the activation analysis allowed to determine the following environmental and safety parameters.

Decay heat

Decay heat is calculated to ensure that adequate cooling is available for stored coolant at all times. According to limits employed in previous studies, no-active cooling is required if the decay heat is below $10 \mathrm{~W} / \mathrm{m}^{3}$, dry cooling is sufficient if it is between $10 \mathrm{~W} / \mathrm{m}^{3}$ and $2 \mathrm{~kW} / \mathrm{m}^{3}$, and wet cooling is required above $2 \mathrm{~kW} / \mathrm{m}^{3}$ [29].

\section{Contact dose rate}

The contact dose rate is measured to determine the feasibility of recycling the ternary alloy. The proposed limits for fusion systems are $10 \mu \mathrm{Sv} / \mathrm{h}$ for hands on operation, and $10 \mathrm{mSv} / \mathrm{h}$ for remote handling [30]. For this study, the hands on limit was disregarded since the coolant after shutdown could be drained down into cooling tanks. Only remote handling of the breeder/coolant is considered.

\section{Waste disposal rating}

The waste disposal rating (WDR) determines whether the alloy meets the concentration limits for Class C low-level waste (LLW) under NRC 10CFR1 [31]. It is defined as the sum of the ratio of the concentration of a particular isotope to the maximum allowed concentration of that isotope for Class $\mathrm{C}$, taken over all isotopes of the alloy. If the WDR $<1$, the mixture is considered LLW.

\section{Accident dose}

DOE Fusion Safety Standards limit dose in accident scenario to $10 \mathrm{mSv}$ [32]. This value refers to a 50 year committed effective dose calculated to the most exposed individual at the site boundary $(1 \mathrm{~km})$ with contributions from direct cloudshine, and inhalation during plume passage [33]. The contribution from groundshine is not included in the limit because it doesn't contribute directly to the accident and is more of public health measure. Nevertheless, this study will include groundshine for more conservative results. The accident dose (AD) is calculated by multiplying the following three factors:

$$
A D(S v)=\text { Radioactivity }(B q) \times D C F\left(\frac{S v}{B q}\right) \times R F
$$

The radioactivity is obtained from $\mathrm{ACAB}$ calculations. Dose conversion factors (DCFs) for typical radionuclides released from IFE activation of structural materials were specifically calculated using the dispersion and accident consequences software MACCS2 [33]. For this study, the DCFs were chosen with standard conditions such as a 1 $\mathrm{km}$ boundary, conservative weather, ground release, and no building wake effects. The release fractions (RF) are usually derived from the combination of detailed modeling of the accident and measurements of the material mobilization under such accident conditions. This determines how much of the component escapes from the accident, and what percentage of that is released into the atmosphere and poses a hazard to the public. Modeling detailed accident scenarios for each alloy would take too long. Approximated release fractions, instead, were utilized. Such release fractions characterize an isotope's mobilization and volatility according to five categories [34]:

1. Elements with species gaseous at room temperature: high mobility $-100 \%$

2. Elements with species gaseous at typical reactor operating temperatures $\left(<500^{\circ} \mathrm{C}\right)-30 \%$

3. Elements with species gaseous at modest accident temperatures $\left(<1000^{\circ} \mathrm{C}\right)-10 \%$

4. Elements with species gaseous at severe accident temperature $\left(<1500^{\circ} \mathrm{C}\right)-3 \%$

5. Elements with species (pure element or oxide) at severe gaseous temperatures such as tokamak dust erosion or oxide spallation $-1 \%$

\section{Results and Discussion}

\subsection{Preliminary Evaluations}

In order to understand the behavior of different elements in the blanket that would infer the behavior of ternaries when combined, preliminary evaluations were performed. Using a representative blanket neutron flux (obtained from MCNP calculations with a LiSnZn alloy), effective q-value, effective absorption cross section, and effective 
$(\mathrm{n}, \mathrm{xn})$ cross section were calculated for an initial set of elements ( $\mathrm{Na}, \mathrm{Mg}, \mathrm{Al}, \mathrm{Si}, \mathrm{Ca}, \mathrm{Ti}, \mathrm{Cu}, \mathrm{Zn}, \mathrm{Ga}, \mathrm{Sr}, \mathrm{Pd}, \mathrm{Ag}, \mathrm{In}$, $\mathrm{Sn}, \mathrm{Sb}, \mathrm{Ba}, \mathrm{Au}, \mathrm{Pb}$, and $\mathrm{Bi}$ ) selected by the LLNL based on thermodynamics properties [35]. Their values are reported in Table 2 .

Table 2: Effective cross sections and q-values for selected elements.

\begin{tabular}{|l|c|c|c|}
\hline Element & $\begin{array}{c}\text { q-value, } \\
\text { MeV }\end{array}$ & $\begin{array}{c}\text { Absorption cross } \\
\text { section, b }\end{array}$ & $\begin{array}{c}\text { (n,xn) cross } \\
\text { section, b }\end{array}$ \\
\hline $\mathrm{Li}$ & 4.67 & $7.37 \mathrm{E}-02$ & $1.53 \mathrm{E}-03$ \\
$\mathrm{Li}-6$ & 4.78 & $9.77 \mathrm{E}-01$ & $0.00 \mathrm{E}+00$ \\
$\mathrm{Li}-7$ & -7.16 & $4.63 \mathrm{E}-04$ & $1.66 \mathrm{E}-03$ \\
$\mathrm{Na}$ & -1.79 & $1.53 \mathrm{E}-02$ & $5.30 \mathrm{E}-04$ \\
$\mathrm{Mg}$ & -2.13 & $2.35 \mathrm{E}-02$ & $4.77 \mathrm{E}-03$ \\
$\mathrm{Al}$ & -0.96 & $1.57 \mathrm{E}-02$ & $1.21 \mathrm{E}-04$ \\
$\mathrm{Si}$ & -2.67 & $3.21 \mathrm{E}-02$ & $9.30 \mathrm{E}-04$ \\
$\mathrm{Ca}$ & 0.48 & $5.39 \mathrm{E}-02$ & $5.31 \mathrm{E}-04$ \\
$\mathrm{Ti}$ & 3.47 & $2.78 \mathrm{E}-02$ & $1.45 \mathrm{E}-02$ \\
$\mathrm{Cu}$ & 5.12 & $7.24 \mathrm{E}-02$ & $2.20 \mathrm{E}-02$ \\
$\mathrm{Zn}$ & 4.44 & $5.97 \mathrm{E}-02$ & $1.24 \mathrm{E}-02$ \\
$\mathrm{Ga}$ & 5.45 & $1.33 \mathrm{E}-01$ & $3.25 \mathrm{E}-02$ \\
$\mathrm{Sr}$ & 1.97 & $1.59 \mathrm{E}-02$ & $3.11 \mathrm{E}-02$ \\
$\mathrm{Pd}$ & 6.86 & $3.72 \mathrm{E}-01$ & $7.24 \mathrm{E}-02$ \\
$\mathrm{Ag}$ & 6.37 & $6.50 \mathrm{E}-01$ & $6.36 \mathrm{E}-02$ \\
$\mathrm{In}$ & 6.2 & $6.68 \mathrm{E}-01$ & $6.76 \mathrm{E}-02$ \\
$\mathrm{Sn}$ & 4.18 & $7.51 \mathrm{E}-02$ & $7.34 \mathrm{E}-02$ \\
$\mathrm{Sb}$ & 5.61 & $3.65 \mathrm{E}-01$ & $6.82 \mathrm{E}-02$ \\
$\mathrm{Ba}$ & 3.55 & $5.14 \mathrm{E}-02$ & $7.99 \mathrm{E}-02$ \\
$\mathrm{Au}$ & 5.76 & $6.98 \mathrm{E}-01$ & $1.07 \mathrm{E}-01$ \\
$\mathrm{~Pb}$ & 1.76 & $5.58 \mathrm{E}-03$ & $1.17 \mathrm{E}-01$ \\
$\mathrm{Bi}$ & 1.64 & $6.37 \mathrm{E}-03$ & $1.14 \mathrm{E}-01$ \\
\hline
\end{tabular}

The effective q-value was calculated as:

$$
\begin{gathered}
Q_{e}=\frac{\sum_{i=1}^{N_{e}} a^{i} \sum_{r} Q_{r}^{i} \sigma_{r}^{i}}{\sum_{i=1}^{N_{e}} a^{i} \sum_{r} \sigma_{r}^{i}} \\
Q_{(n, x n)}^{i}=Q_{(n, x n)}+x Q_{e}^{L i}
\end{gathered}
$$

where $i$ is the specific isotope of an element, $r$ is the type of neutron reaction, $\sigma$ is the cross section, $Q$ is the q-value, $a$ is the abundance fraction, and $\mathrm{Ne}$ is the number of isotopes in the element. From a neutronics perspective, it is desirable to have low absorption cross section to reduce neutron loss in unwanted reactions that would inhibit the TBR and EMF. A large (n,xn) cross section is necessary to increase the number of neutrons in the blanket which will enhance the TBR. It is assumed that the $\mathrm{x}(2$ or 3$)$ neutrons generated in $(\mathrm{n}, \mathrm{xn})$ reactions will go on to be absorbed by lithium and this is accounted for in the q-value defined in Equation (3). Lastly, a high effective q-value is crucial to ensure an adequate EMF. The last two features, $(\mathrm{n}, \mathrm{xn})$ cross section and Q-value, contradict each other as $(n, x n)$ reactions are endothermic, but overall the availability of extra neutrons upon ( $n, x n)$ reaction may compensate the loss of energy due to subsequent exothermic reaction with ${ }^{6} \mathrm{Li}$ and/or other alloy constituents. Additionally, the low absorption cross section also contradicts the high Q-value since heat is produced by absorption cross sections such as $(\mathrm{n}, \gamma)$. This is why a ternary alloy is ideal; the properties of one element can complement the properties of another and result in a successful ternary system. For example, an alloy that possesses a low absorption cross section and high multiplication cross section, such as $\mathrm{Pb}$, can be combined with an element that has a higher 
Q-value, such as $\mathrm{Zn}$, even if its absorption cross section is not as low compared to a few other elements. Many ternary combinations can be deduced from the properties of all the elements in Table 2. Results reported in Table 2 show that: $\mathrm{Pb}$ and $\mathrm{Bi}$ are desirable elements for their low absorption and high $(\mathrm{n}, \mathrm{xn})$ cross sections; of the elements with high q-value, $\mathrm{Sn}, \mathrm{Zn}, \mathrm{Cu}$, and $\mathrm{Ti}$ are to be preferred for their relative low absorption;

The elements above were also observed in combination with lithium. Binary alloys were analyzed using the MCNP blanket model and varying the lithium concentration from 0 to $100 \%$ at $5 \%$ intervals. This analysis assumed 1.02 and 1.1 as lower limits for TBR and EMF, respectively. Figure 3 shows example results for LiSn and LiPb binary alloys (a complete set is provided in reference 36). It is observed that: (1) $\mathrm{Ba}, \mathrm{Sn}, \mathrm{Sr}$, and Ti offer the widest range of acceptable lithium concentrations; (2) $\mathrm{Bi}$ and $\mathrm{Pb}$ barely do not meet the EMF requirement, but provide very large TBR even at low concentration of lithium, due to enhanced $(\mathrm{n}, \mathrm{xn})$ reactions. Studies in the past demonstrated the potential of $\mathrm{LiPb}$ as a coolant and breeder. However, the focus was usually on TBR and possible ways to maximize it such as by increasing the ${ }^{6} \mathrm{Li}$ enrichment [37]; (3) Pd, In, Au, and $\mathrm{Ag}$ feature a narrow acceptable range, but a relatively large EMF; (4) $\mathrm{Ga}, \mathrm{Cu}, \mathrm{Sb}$ and $\mathrm{Zn}$ are in the mid-range of acceptable lithium compositions with EMFs slightly higher than 1.1 but no greater than 1.2; (5) Sb, Pd and Au have very narrow acceptable ranges and limited EMF; (6) $\mathrm{Na}, \mathrm{Mg}, \mathrm{Al}, \mathrm{Ca}$, and Si never meet both constraints, mainly due to their detrimental effect on EMF. This results are in line with the observations made from the analysis on individual elements.

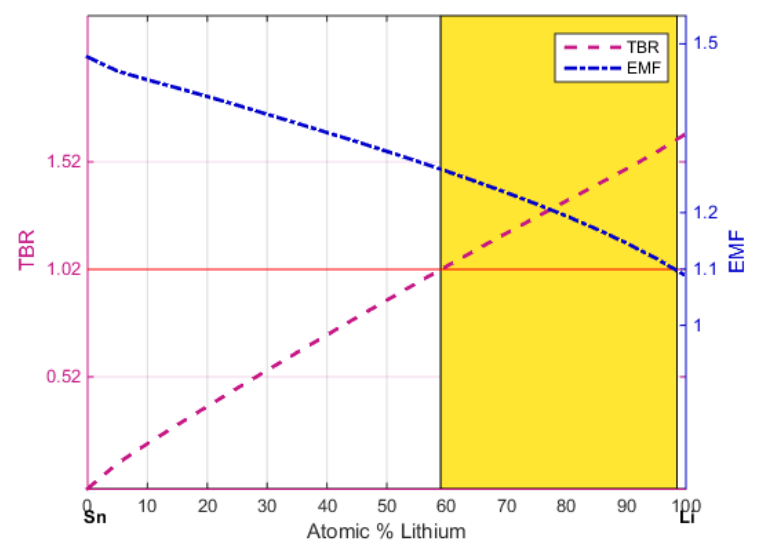

(a)

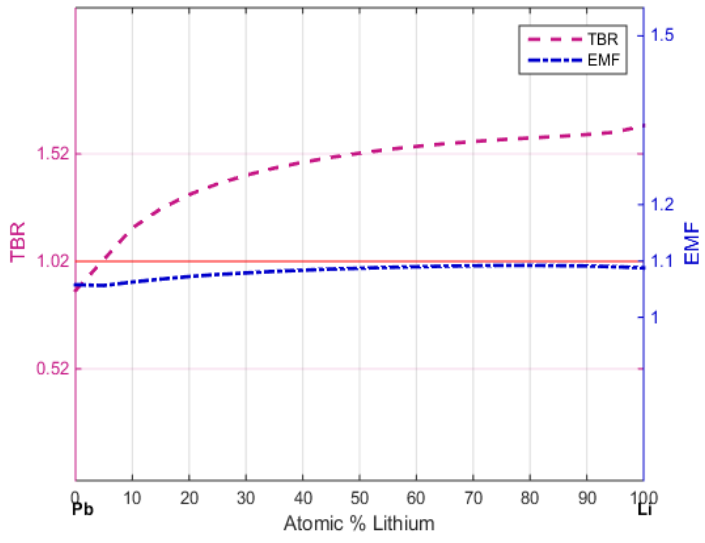

(b)

Figure 3: TBR and EMF for lithium (a) LiSn and (b) LiPb alloys as a function of lithium concentration; the horizontal red line coincides with the minimum value for both TBR (1.02) and EMF (1.10), the shaded yellow area indicates the range of lithium concentration within which both constraints are met.

\subsection{Tritium breeding and energy multiplication}

TBR and EMF were evaluated for 55 lithium ternary alloys as a function of their composition. Each alloy was evaluated according to three different TBR and EMF criteria:

- Aggressive: lowest achievable TBR - 1.02 and highest EMF - 1.2. This category pushes limits to ideal conditions; a TBR that accounts for the least amount of losses and a high EMF to decrease the cost of electricity.

- Conservative: high TBR - 1.1 and low EMF - 1.1. More on the other side of the spectrum, the TBR is high to account for losses, and EMF puts the lowest demand to produce power.

- Semi-conservative (SC): TBR - 1.05 and EMF - 1.1. The TBR here is lowered from the conservative constrain above.

Results containing the range lithium concentrations for various ternary alloys that meet each of the three sets of criteria are illustrated in Figure 4. 


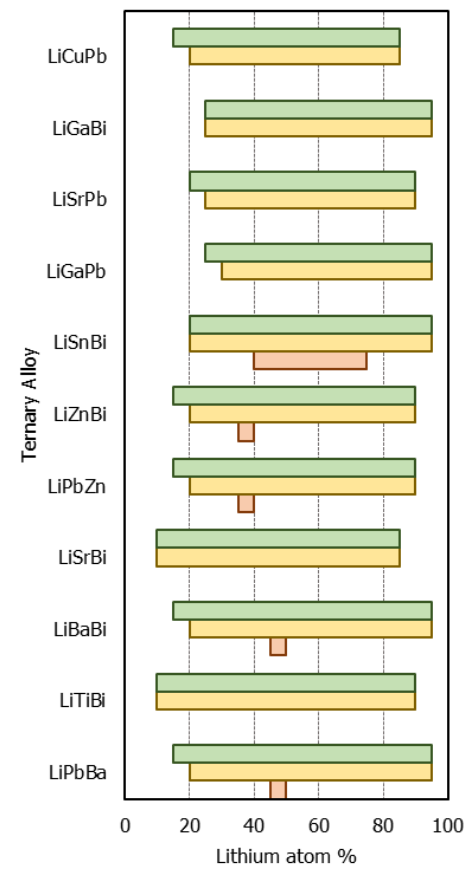

$\square$ Agressive $\square$ Conservative $\square$ Semi-Conservative

(a)

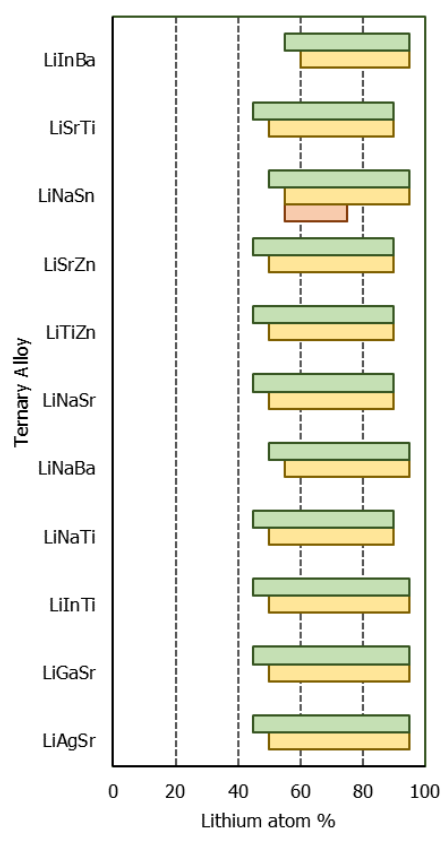

$\square$ Aggressive $\square$ Conservative $\square$ Semi-Conservative

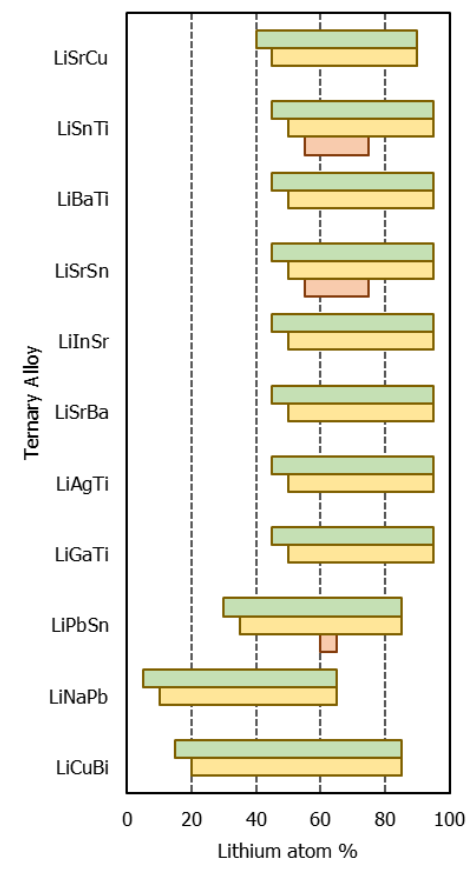

$\square$ Aggressive $\square$ Conservative $\square$ Semi-Conservative

(b)

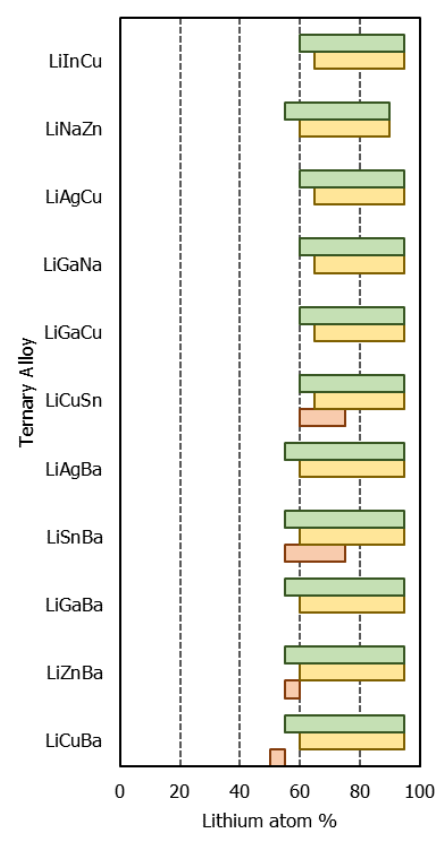

$\square$ Aggressive $\square$ Conservative $\square$ Semi-Conservative

(d) 


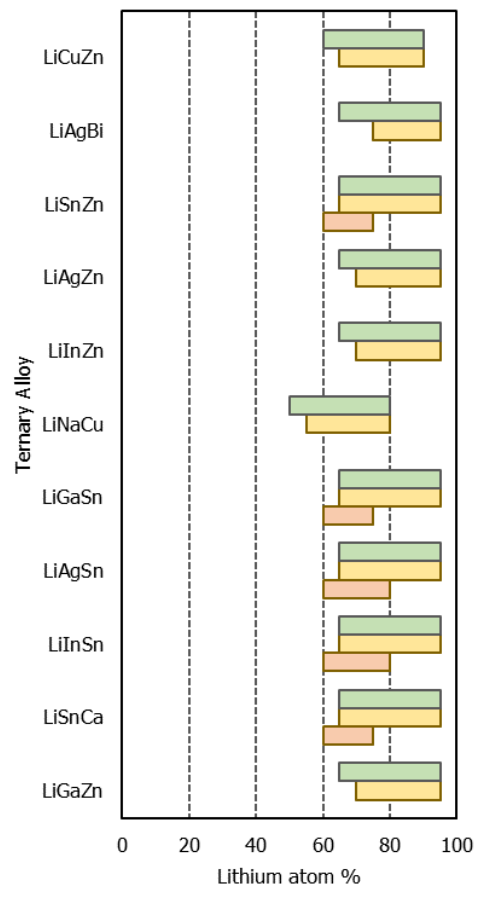

$\square$ Aggressive $\square$ Conservative $\square$ Semi-Conservative

(e)

Figure 4: Range of lithium (atom \%) for each ternary alloy that meet specific TBR and EMF criteria. Aggressive: TBR 1.02, EMF 1.2. Conservative: TBR 1.1, EMF 1.1. Semi-conservative: TBR 1.05, EMF 1.1. When an alloy does not meet one of the criteria at any composition, it is left blank.

All the alloys in Figure 4 meet both the conservative and semi-conservative criteria. The aggressive constrains are mostly met by alloys containing tin (and barium in one case) due to the fact that it has all three desirable properties, a high q-value, low absorption cross section, and high ( $\mathrm{n}, \mathrm{xn})$ cross section. This enhances the TBR but more specifically the EMF; most other alloys cannot reach EMFs that are any higher than 1.15. A few Ba-containing alloys and LiPbZn also meet the aggressive criteria for the same reasons. As predicted, the conservative and semiconservative constrains with the widest range of lithium concentrations were met by elements that performed well in the binary analysis such as barium, tin, and strontium, with lead or bismuth. Elements that have a combination of higher q-value and lower absorption cross section such as zinc will perform adequately when combined with high neutron multipliers such as bismuth, or elements with similar or better attributes, i.e. barium. Even gallium, whose absorption cross section is on the higher end but has above average q-value, yields satisfactory results with the elements formerly mentioned, specifically neutron multipliers. The ternaries in Figure 5 give a closer look at some of these alloys. Although the ranges for which LiNaSn and LiSnZn alloys meet the limits are not as large as some of the other alloys, they do meet all three categories. Ternary diagram results for all the alloys in Figure 4 are found in reference 36 . 


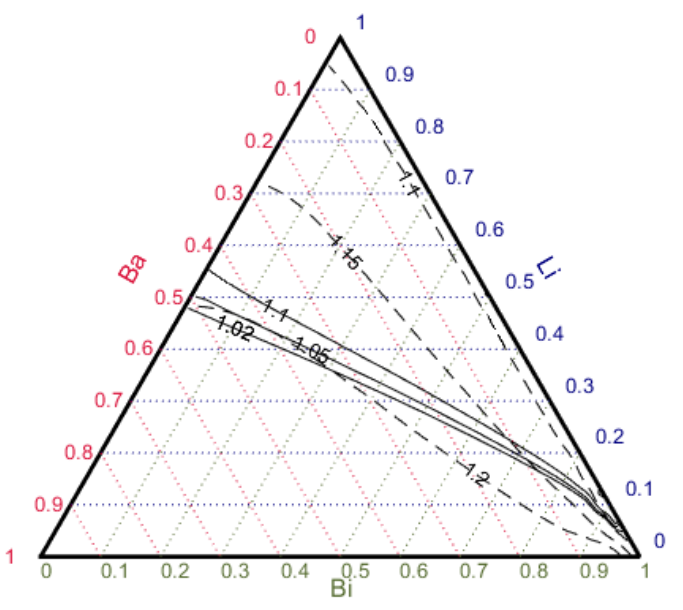

(a)

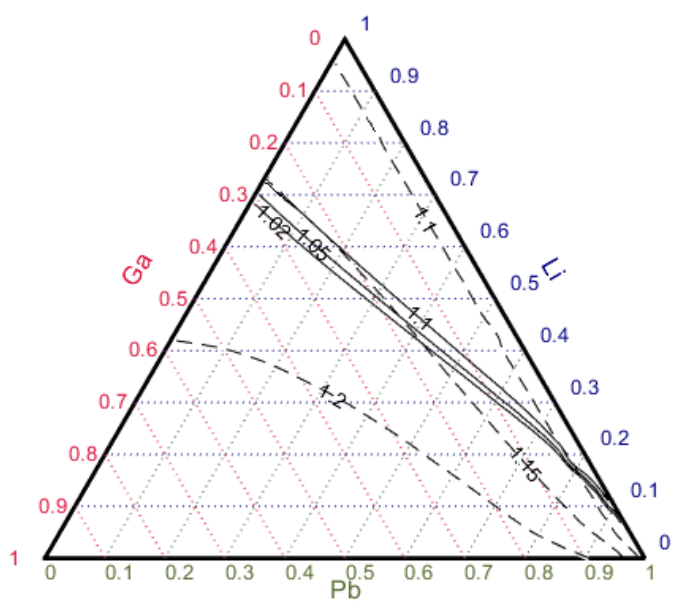

(c)

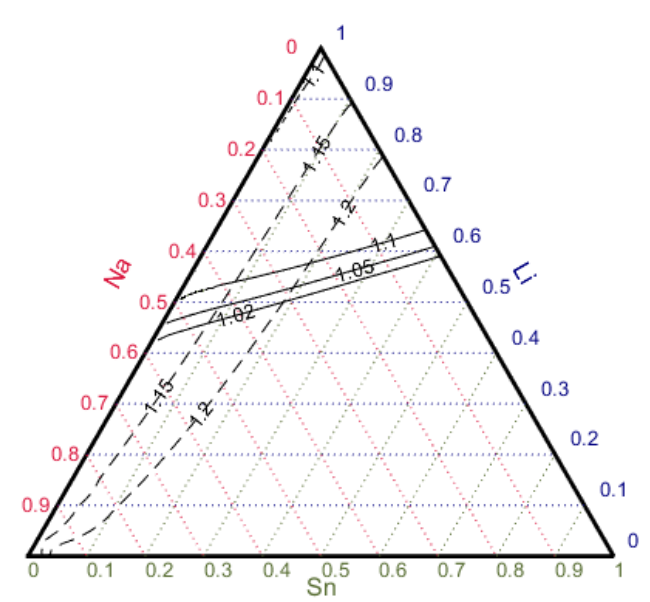

(e)

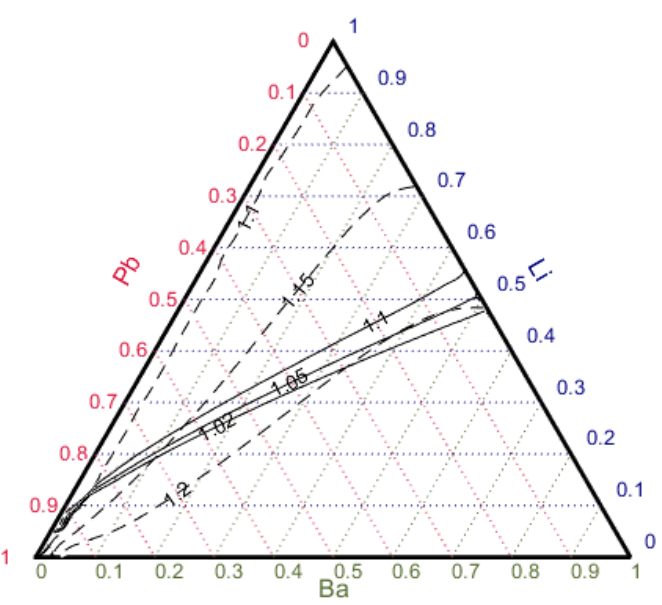

(b)

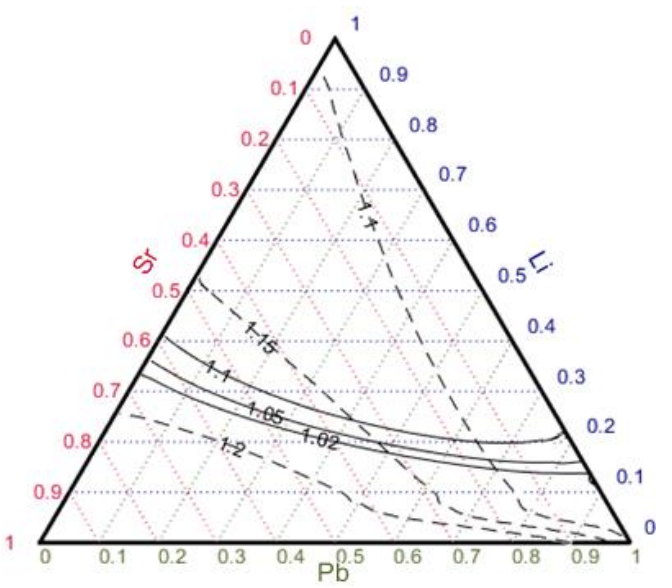

(d)

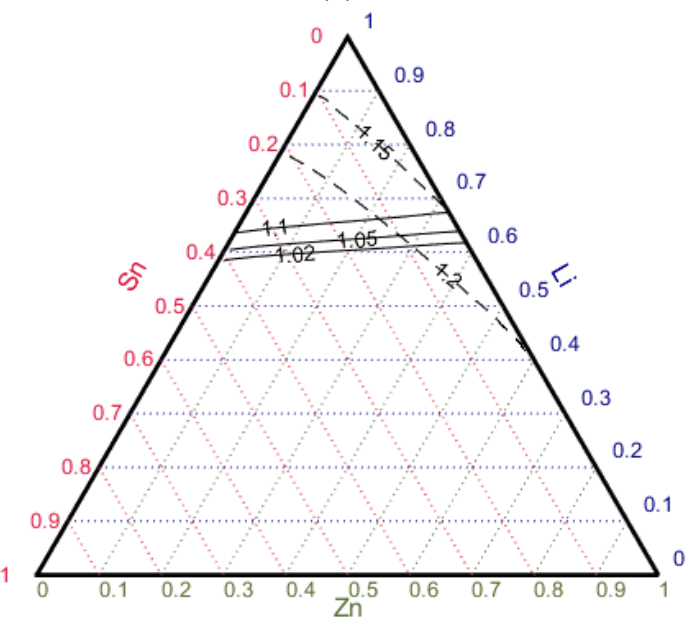

(f)

Figure 5: Ternary Plots for (a) LiBaBi, (b) LiPbZn, (c) LiGaPb, (d) LiSrPb, (e) LiNaSn, and (f) LiSnZn; solid lines represent TBR; dotted lines represent EMF. 
The difference in lithium concentrations between each increase of TBR is not as significant as the change in EMF. Between TBRs of 1.02 and 1.1, respectively, the lithium concentration increases by less than $10 \%$. This allows us to change the TBR constrains if necessary while still maintaining a similar minimum lithium concentration to reduce chemical reactivity. The increase of EMF from 1.1 to 1.2 is dependent on each individual alloy; smaller differences occur for alloys with higher q-values such as tin, zinc and gallium. Nevertheless, to increase the EMF for all alloys, the lithium concentration must be lowered by several percent for less absorption in the lithium and more absorption in the other components. As a result, all the alloys in Figure 5 other than tin, barely, if at all, meet any of the TBR limits with an EMF of 1.2.

\subsection{Lithium enrichment}

In order to further minimize the amount of lithium in the alloys and to increase TBR, the sensitivity to the concentration of lithium- 6 was tested. The $(n, t)$ cross section of ${ }^{6} \mathrm{Li}$ covers a wide range of energies as opposed to ${ }^{7} \mathrm{Li}$, whose cross section only occurs in the high energy range; therefore, enriching the alloy in ${ }^{6} \mathrm{Li}$ increases neutron absorption in it and boosts TBR. LiSnZn was utilized for this enrichment sensitivity study. The chosen composition (65\% Li, $25 \% \mathrm{Sn}, 10 \% \mathrm{Zn}$ ) meets all three sets of criteria described in the previous Section. ${ }^{6} \mathrm{Li}$ 's concentration was increased from natural (7.5\%) to $90 \%$ with increments of 5\%. Figure 6 shows that the EMF rapidly drops with increasing enrichment whereas TBR increases. The EMF exponentially decreases until $40 \%{ }^{6} \mathrm{Li}$, which is about where the TBR reaches its maximum. At such maximum (40\%), the TBR is about $20 \%$ higher than with natural lithium. After this point the TBR becomes saturated and starts to slightly linearly decrease due to the lack of ${ }^{7} \mathrm{Li}(\mathrm{n}, \mathrm{n}$ ' $\mathrm{T})$ reactions. The ${ }^{7} \mathrm{Li}(\mathrm{n}, \mathrm{n}$ ' $\mathrm{T})$ reaction rate linearly decreases as a function of ${ }^{6} \mathrm{Li}$ enrichment, shown in Figure 6. Before $40 \%$ the ${ }^{6} \mathrm{Li}(\mathrm{n}, \mathrm{T})$ reactions are increasing at a greater rate than ${ }^{7} \mathrm{Li}(\mathrm{n}, \mathrm{n}$ ' $\mathrm{T})$ reactions, overcoming them to allow the total TBR to increase. However, after $40 \%$, the lack of additional neutrons from ${ }^{7} \mathrm{Li}(\mathrm{n}, \mathrm{n}$ ' $\mathrm{T})$ reactions prevent ${ }^{6} \mathrm{Li}$ from producing tritium at the same rate as it did with lower enrichments. This, plus the lack of tritium production from ${ }^{7} \mathrm{Li}$ causes the total TBR to decrease at enrichments greater than $40 \%$. The (n,xn) reaction rate, influenced by tin, only slight decreases and does not have a strong influence on the behavior of the TBR.

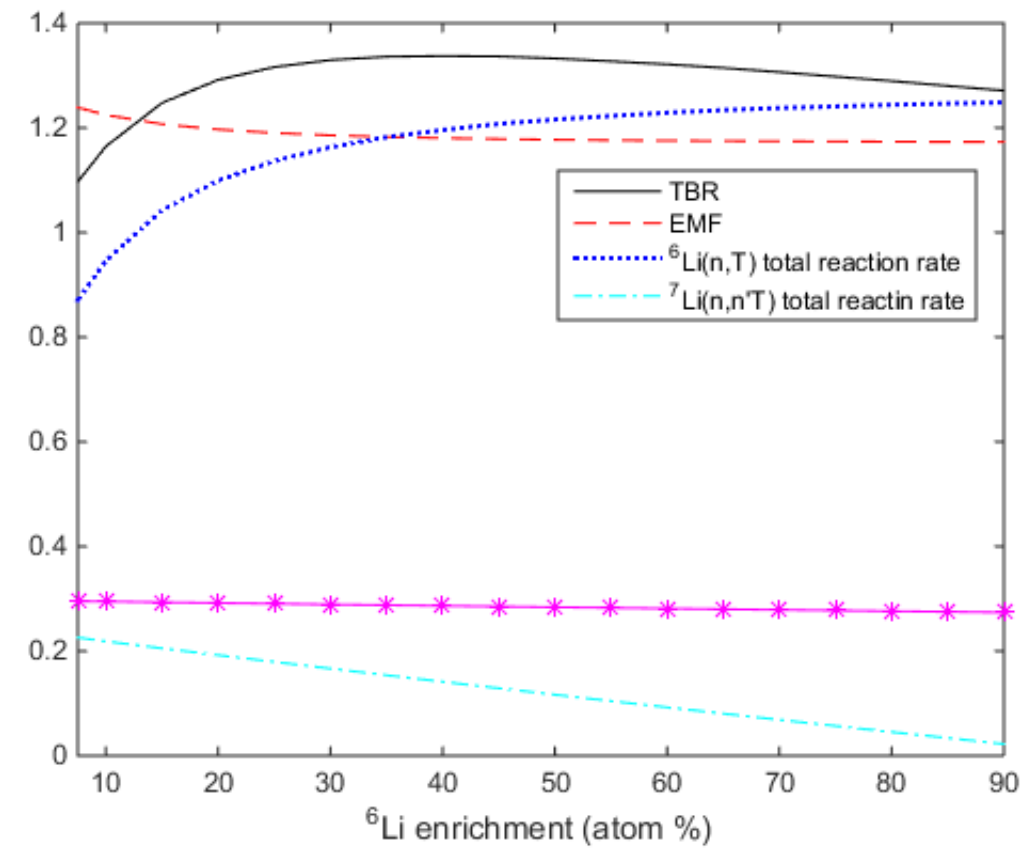

Figure 6. TBR,EMF, and $(\mathrm{n}, \mathrm{T})$ and $(\mathrm{n}, \mathrm{xn})$ reaction rates as a function of ${ }^{6} \mathrm{Li}$ concentration in lithium for $\mathrm{Li}(65 \%) \operatorname{Sn}(20 \%) \mathrm{Zn}(15 \%)$ alloy.

Figure 7 displays the range of total lithium concentrations in the LiSnZn alloy that meet each of the previously discussed criteria for three enrichment cases: natural, $40 \%$, and $90 \%$. The minimum lithium concentrations for each of the cases decrease as lithium enrichment increases. For example, the aggressive case decreases from 60 atom \% for natural enriched lithium to 25 atom $\%$ for $40 \%$ enriched lithium. It decreases even further to 15 atom $\%$ total 
when lithium is enriched to $90 \%$. Nevertheless, the case with $40 \%$ enriched lithium meets this criterion for a range of $35 \%$ of lithium concentrations ( 25 atom \% to 60 atom \% Li) as opposed to the $10 \%$ range in the case of $90 \%$ enrichment (15 atom \% to 25 atom\% Li). Additionally, the EMF is largely compromised as enrichment increases and thus, it is much harder for alloys of different concentrations in the $90 \%$ enriched case to meet the $1.2 \mathrm{EMF}$ for the aggressive category. This is visualized in Figure 8 where ternary diagrams with ${ }^{6} \mathrm{Li}$ enriched at $40 \%$ and $90 \%$ are shown. It can also be seen in the ternaries how, for a constant lithium concentration, the TBR decreases when the amount of zinc in the alloy increases. This is due to the decrease of tin $(\mathrm{n}, \mathrm{xn})$ reactions, which lowers the neutron economy and reduces the number of $\operatorname{Li}(\mathrm{n}, \mathrm{T})$ reactions. In addition, the phenomenon becomes more pronounced in the $90 \%$ enriched $\mathrm{Li}$ ternary due to the lack of ${ }^{7} \mathrm{Li}(\mathrm{n}, \mathrm{n}$ 'T) reactions, which lowers the TBR as previously described. As a result, the TBR at $65 \% \mathrm{Li}, 20 \% \mathrm{Sn}$, and $15 \% \mathrm{Zn}$ will be lower (1.2) at $90 \%$ enriched lithium, than at $40 \%$ (1.31). Minimizing the lithium concentration without lowering the energy multiplication factor and increasing the cost too much should be considered when selecting the lithium enrichment.

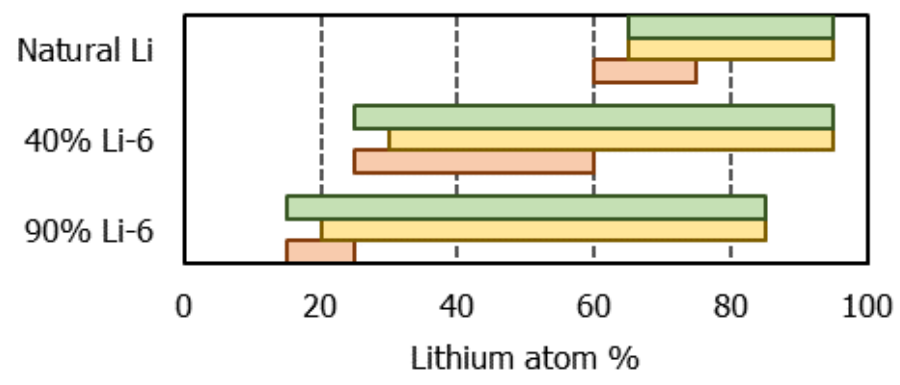

$\square$ Aggressive $\square$ Conservative $\square$ Semi-Conservative

Figure 7. Range of lithium (atom\%) for LiSnZn with natural, 40\%, and 90\% enrichment, that meet specific TBR and EMF criteria. Aggressive: TBR 1.02, EMF 1.2. Conservative: TBR 1.1, EMF 1.1. Semi-conservative: TBR 1.05, EMF 1.1.

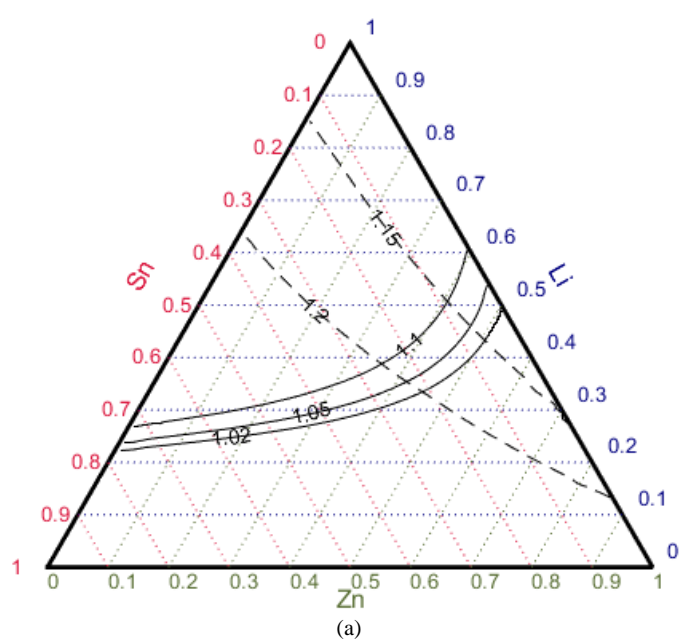

Figure 8. Ternary diagrams for LiSnZn with lithium enriched to (a) 40\% and (b) 90\%; the solid lines represent TBR; dotted lines represent EMF.

\subsection{Activation Analysis}

Eight alloys were chosen for an extensive activation analysis: $\mathrm{LiBaBi}, \mathrm{LiPbBa}, \mathrm{LiSnZn}, \mathrm{LiCuPb}, \mathrm{LiGaPb}, \mathrm{LiSrPb}$, $\mathrm{LiPbZn}$, and LiNaSn. These alloys were chosen based on their neutronic performance: alloys with $\mathrm{Pb}$ and $\mathrm{Bi}$ exhibit high neutron multiplication and minimize the amount of lithium in the alloy; alloys with $\mathrm{Sn}$ meet all of the three 
sets of criteria in the previous analysis. The composition for each alloy (Table 3) was selected to meet the conservative or semi-conservative set of criteria. These are all with natural lithium.

Table 3: Compositions of Alloys Chosen for Activation Analysis
\begin{tabular}{|l|c|}
\hline Alloy & Composition (\%) \\
\hline \hline LiBaBi & $20-10-70$ \\
LiPbBa & $25-60-15$ \\
LiSnZn & $65-25-10$ \\
LiCuPb & $40-20-40$ \\
LiGaPb & $35-10-55$ \\
LiSrPb & $30-50-20$ \\
LiPbZn & $30-60-10$ \\
LiNaSn & $55-30-15$ \\
\hline
\end{tabular}

As stated in Section 2.3, the irradiation history for activation is 50 years of operation followed by 300 years of cooling. Results for the parameters described in Section 2.3 are analyzed in the following paragraphs.

\section{Decay heat}

The decay heat is plotted in Figure 9. LiPbBa is the alloy with the lowest decay heat and the only one that can utilize dry cooling right after shutdown. Most of the decay heat in this alloy stems from ${ }^{137 \mathrm{~m}} \mathrm{Ba},{ }^{137} \mathrm{Cs}$, and ${ }^{133} \mathrm{Ba}$. On the contrary, LiBaBi exhibits the highest decay heat due to ${ }^{210} \mathrm{Po}$, a decay product of ${ }^{210} \mathrm{Bi}$ shown in Figure 10(a). The decay heat remains high in this alloy after one and a half years when polonium decays due to contributions from ${ }^{207} \mathrm{Bi}$ and ${ }^{208} \mathrm{Bi}$. During the first year and a half LiBaBi must be wet cooled; afterwards, dry cooling can be utilized. Alloys containing $\mathrm{Sn}$ and $\mathrm{Zn}$ behave fairly similar; $\mathrm{LiPbZn}$ and $\mathrm{LiSnZn}$ have the greatest contribution from ${ }^{65} \mathrm{Zn}$. After one year the activation products of tin do not allow the two tin-containing alloys to decay at the same rate as LiPbZn. Nevertheless, all three of the alloys can be switched from wet cooling to dry after one year. Other lead containing alloys such as $\mathrm{LiSrPb}$ and $\mathrm{LiCuPb}$ decay at faster rates such that dry cooling can be implemented for $\mathrm{LiSrPb}$ in less than a month's time, and for $\mathrm{LiCuPb}$ in less than a week. $\mathrm{LiGaPb}$ is an interesting case $-{ }^{72} \mathrm{Ga}$ causes the decay heat of LiGaPb to be large in the beginning as seen in Figure 10(a). However, it significantly decreases after one week and becomes the alloy with the lowest decay heat. At this time $\mathrm{LiGaPb}$ will not need any additional active cooling. Most of the other alloys will not need active cooling after 50 years with the exception of LiBaBi, who does not meet this limit for 200 years.

\section{Contact dose rate}

Contact dose rates for all the alloys are illustrated in Figure 11. Note that the rates are given per cubic meter, not for the entire volume of the breeder, $4,418 \mathrm{~m}^{3}$. Similar to the decay heat, $\mathrm{LiGaPb}$ has the highest contact dose rate for the first week until ${ }^{72} \mathrm{Ga}$ decays, shown in Figure 12(a). After this time, hypothetically speaking, it would be possible to recycle with the appropriate equipment at least $1 \mathrm{~m}^{3}$ of $\mathrm{LiGaPb}$. Once the gallium alloy decreases, alloys with zinc portray the largest contact dose rates from contributions of ${ }^{65} \mathrm{Zn}$ (Figure 12(a)). LiNaSn is also in the same range of contact dose rates at the beginning before ${ }^{24} \mathrm{Na}$ and ${ }^{22} \mathrm{Na}$ decay, shown in Figure (12(b)). Lead containing alloys such as $\mathrm{LiPbZn}, \mathrm{LiSrPb}$, and $\mathrm{LiPbBa}$, portray the lowest contact dose rates for the first six months. By this time, the contact dose rate of $\mathrm{LiSrPb}$ has significantly decreased due to the decay of ${ }^{85} \mathrm{Sr}$. On the contrary, the decay of LiPbBa occurs much more slowly and LiPbZn decays much later, after five years. At this point the contact dose rates of the other alloys are much lower. The one exception is $\mathrm{LiBaBi}$, whose isotopes decay at the slowest rate of any other alloy, only decreasing the contact dose rate by an order of a magnitude and a half in the first 300 years. Most alloys meet the remote handling limit with $1 \mathrm{~m}^{3}$ of their volume after 10 years. This allows fractions of the blanket to be recycled at a time. Every alloy except $\mathrm{LiPbBa}$, and $\mathrm{LiBaBi}$ will be able to be remotely handled with the entire blanket volume at 100 years. By 300 years, the only alloy that will not meet the $10 \mathrm{mSv} / \mathrm{h}$ constrain with $100 \%$ of its volume is $\mathrm{LiBaBi}$. 
Unlike decay heat and contact dose rates, results for accident dose include the contribution of tritium. Tritium will be separated from the rest of the coolant after shutdown and recycled. Whereas decay heat and contact dose rates are measured after shutdown, a loss of coolant or flow is most likely to occur during normal operation. The accident scenario in this study assumes immediate release of the coolant to the environment without the use of any shielding or containment structure to stop the release. Additionally, it is important to note that results for accident doses, shown in Table 4, are conservative due to the use of the Piet release fractions as opposed to release fractions modeled from real accident scenarios. From the results, ${ }^{210} \mathrm{Po}$ (decay product of ${ }^{210} \mathrm{Bi}$ ) contains a high DCF and causes the accident dose to be the highest in LiBaBi. Alloys containing lead such as LiPbBa and LiPbZn will also be compromised by ${ }^{210} \mathrm{Po}$. Nevertheless, direct production of polonium from bismuth causes the accident dose to be at least three orders of magnitude higher. The accident dose in zinc containing alloys will be dominated by ${ }^{65} \mathrm{Zn}$ due to its high radioactivity and release fraction. The lowest accident doses are from LiPbBa and LiSrPb, being only half of what it is for $\mathrm{LiCuPb}$. With the exclusion of $\mathrm{LiBaBi}$, the accident dose constraint will only be met for all the alloys if about $8000-18,000 \mathrm{~cm}^{3}$ of coolant escapes.

\section{Waste disposal rating}

The last activation parameter accounted for was the WDR to verify that alloys meet requirements for shallow land burial. These are listed in Table 4 for the entirety blanket volume. All the alloys meet the WDR criteria $(<1)$ except for $\mathrm{LiBaBi}$; this is due to ${ }^{208} \mathrm{Bi}$.

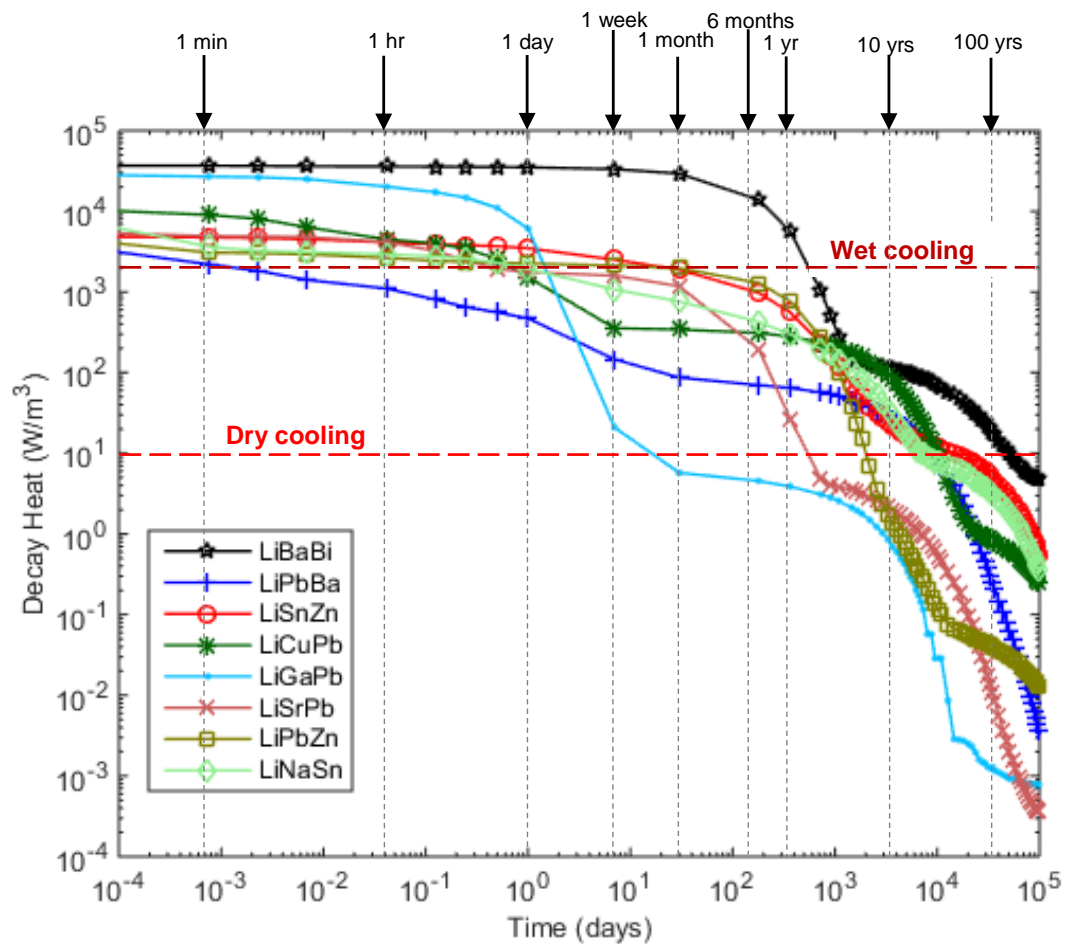

Figure 9. Decay heat $\left(\mathrm{W} / \mathrm{m}^{3}\right)$ as a function of time after irradiation for breeder/coolant ternary alloys. The wet cooling and dry cooling constrains are indicated by the horizontal lines. 


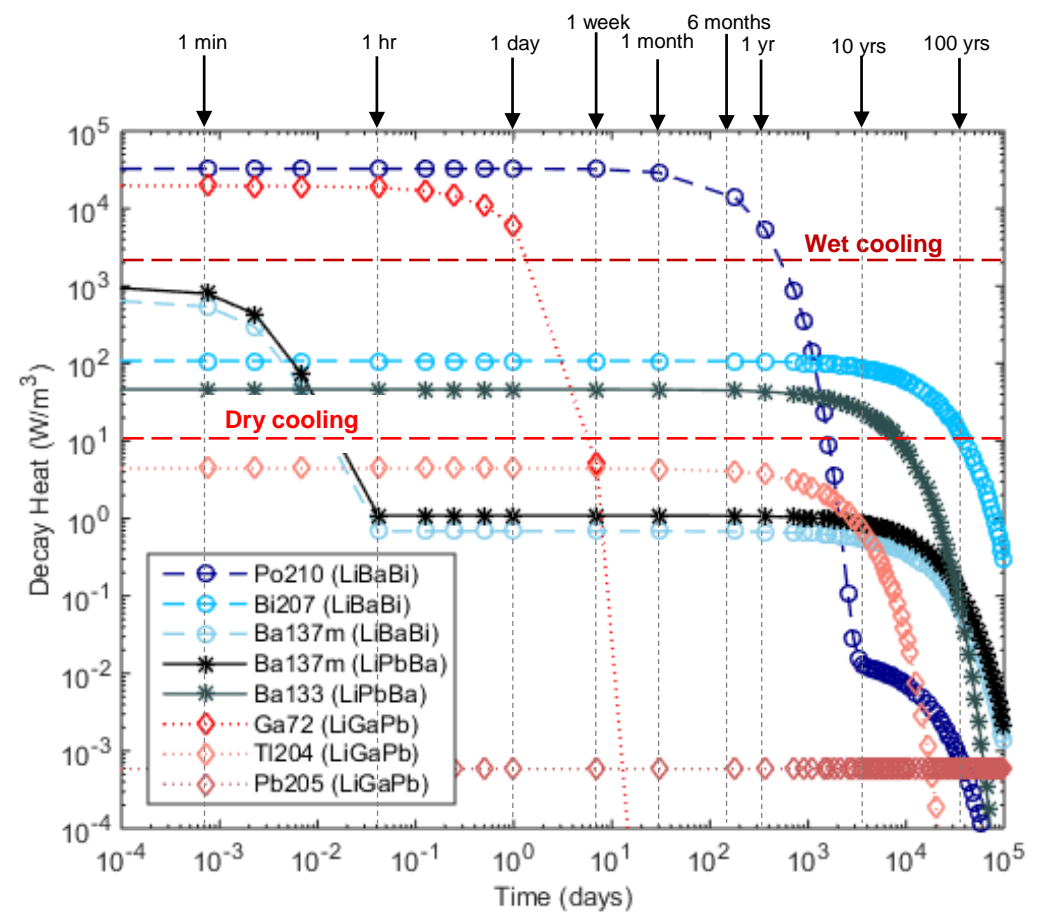

(a)

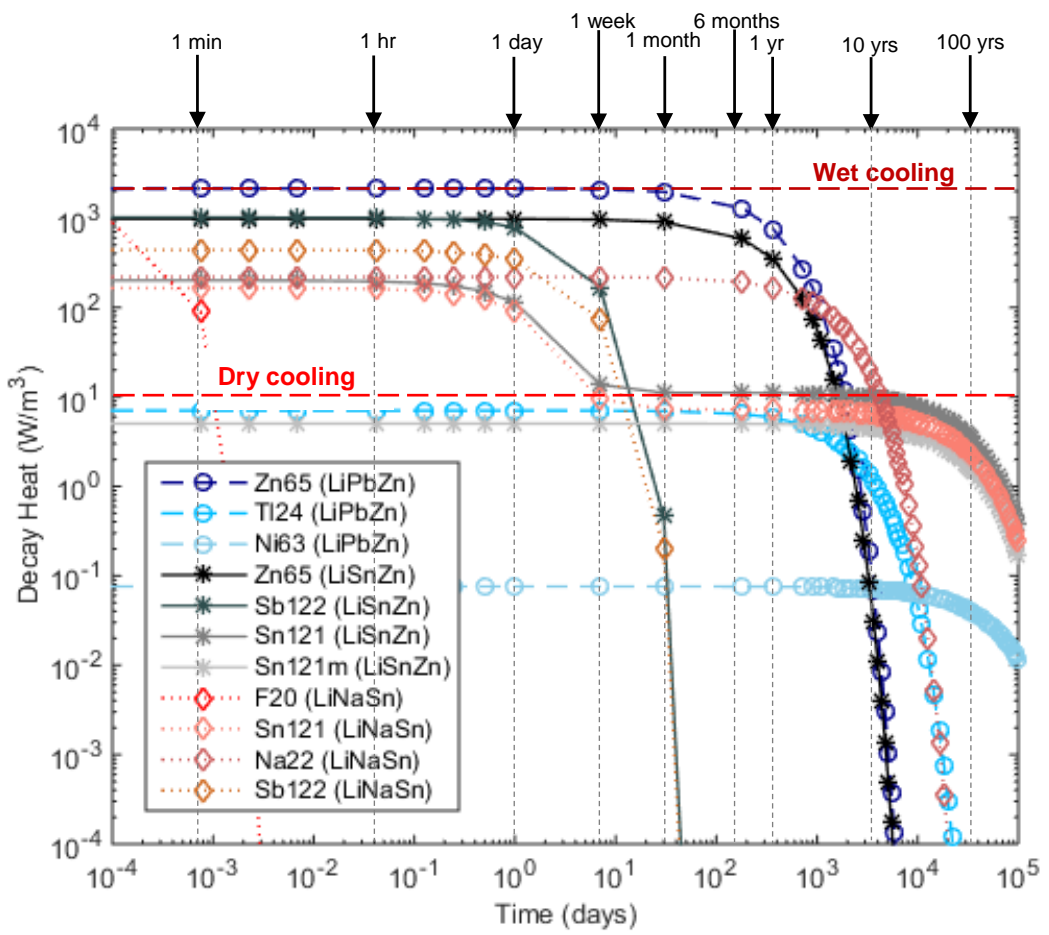

(b)

Figure 10. Isotopics of decay heat $\left(\mathrm{W} / \mathrm{cm}^{3}\right)$ after irradiation for (a) $\mathrm{LiBaBi}, \mathrm{LiPbBa}$, and $\mathrm{LiGaPb}$ and (b) $\mathrm{LiPbZn}$, LiSnZn, and LiNaSn. The wet cooling and dry cooling constrains are indicated by the horizontal lines. 


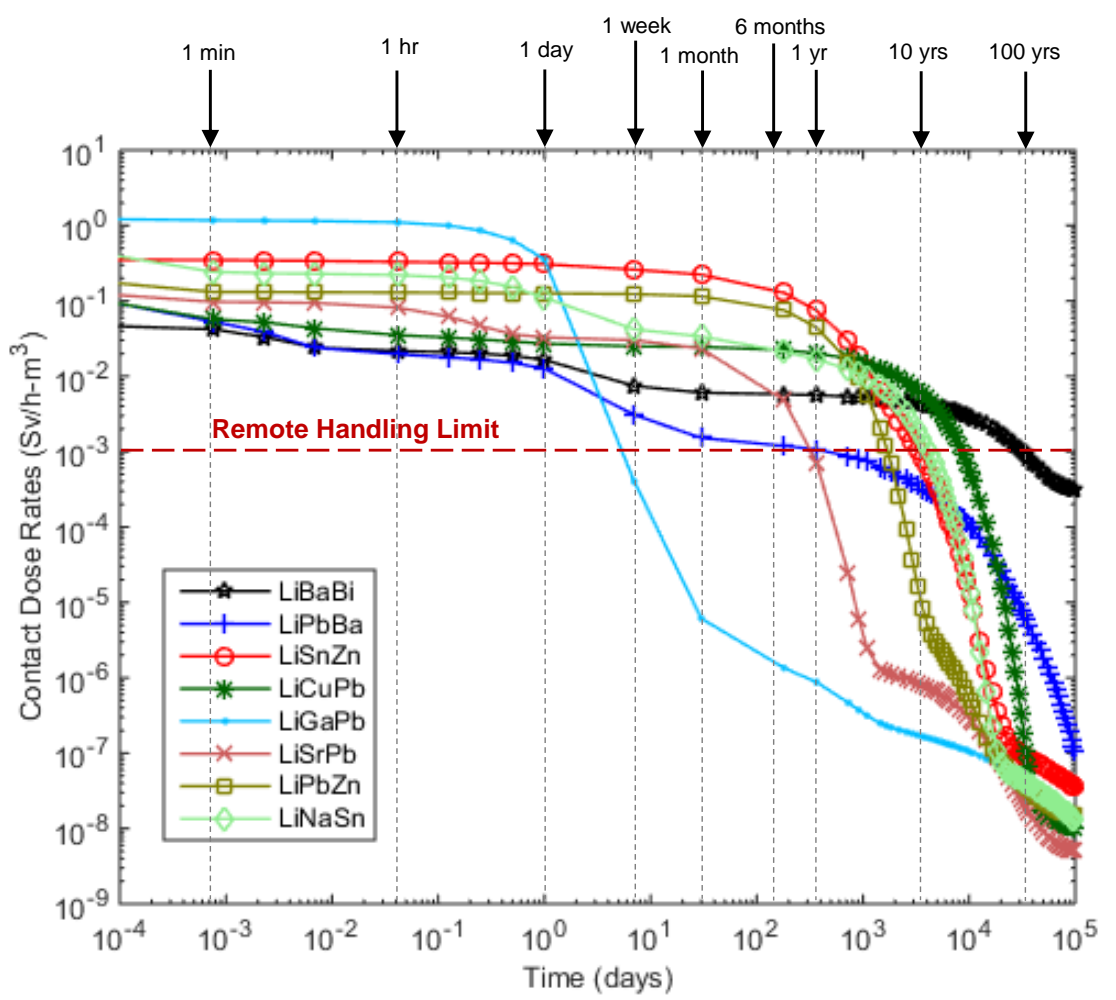

Figure 11. Contact Dose Rates $\left(\mathrm{Sv} / \mathrm{h}-\mathrm{m}^{3}\right)$ as a function of time after irradiation for breeder/coolant ternary alloys.

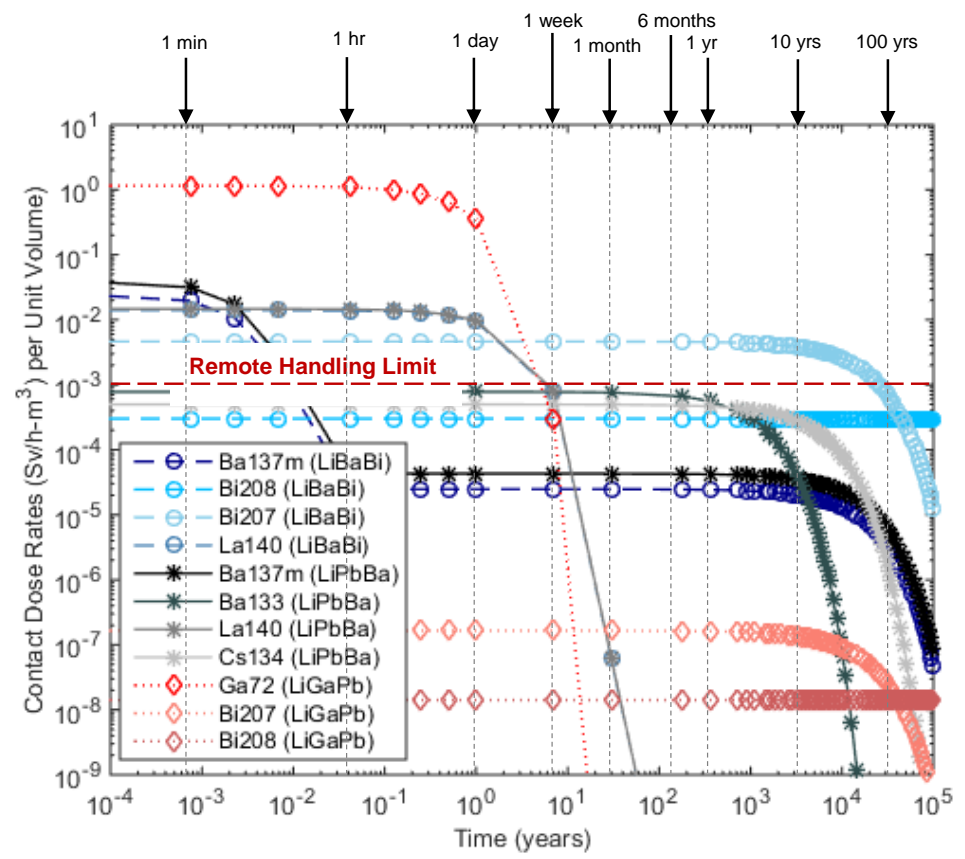

(a) 


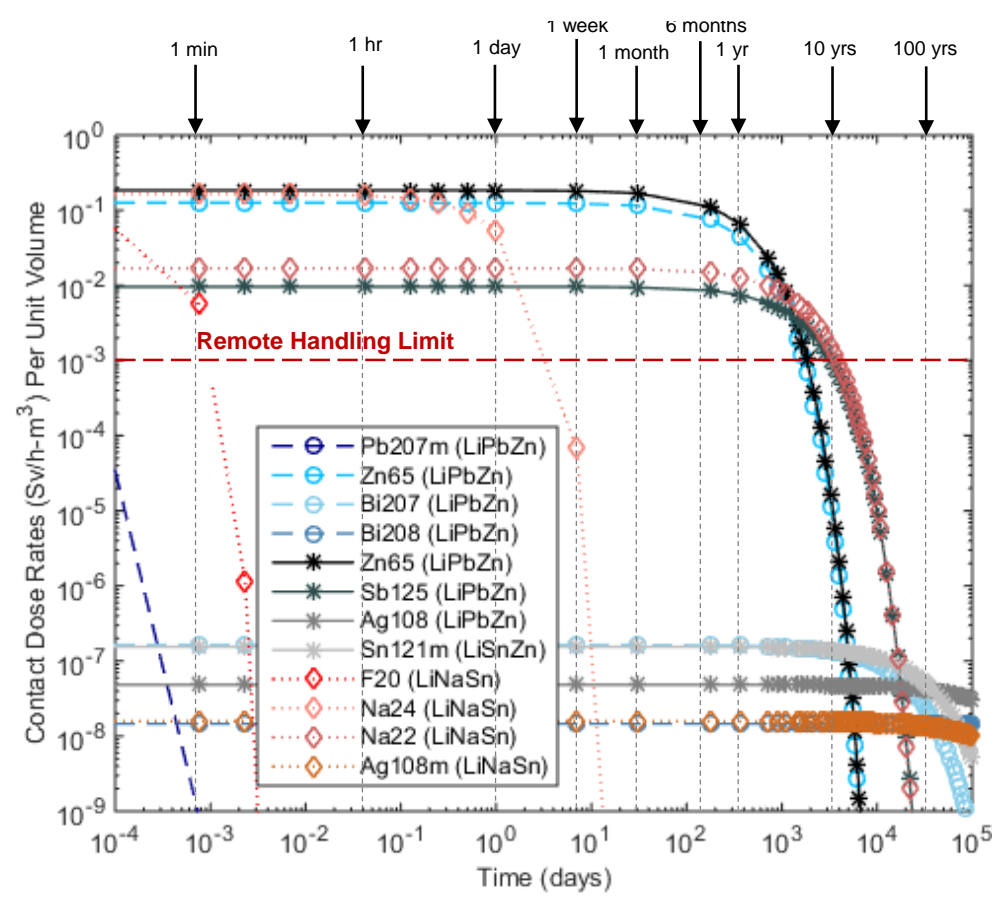

(b)

Figure 12. Isotopics of Contact Dose Rates ( $\mathrm{Sv} / \mathrm{h}$ ) for (a) LiBaBi, LiPbBa, and LiGaPb and (b) LiPbZn, LiSnZn, and LiNaSn.

Table 4. Accident Dose (AD) and Waste Disposal Ratings (WDR) for alloys.

\begin{tabular}{|l|c|c|}
\hline Alloy & AD $\left(\mathbf{m S v} / \mathbf{c m}^{3}\right)$ & WDR \\
\hline $\mathrm{LiBaBi}$ & 1.54 & 3410 \\
$\mathrm{LiPbBa}$ & $5.64 \times 10^{-4}$ & 0.19 \\
$\mathrm{LiSnZn}$ & $1.08 \times 10^{-3}$ & 0.09 \\
$\mathrm{LiSrPb}$ & $5.77 \times 10^{-4}$ & 0.05 \\
$\mathrm{LiGaPb}$ & $1.00 \times 10^{-3}$ & 0.18 \\
$\mathrm{LiCuPb}$ & $1.17 \times 10^{-3}$ & 0.15 \\
$\mathrm{LiPbZn}$ & $1.25 \times 10^{-3}$ & 0.2 \\
$\mathrm{LiNaSn}$ & $6.62 \times 10^{-4}$ & 0.07 \\
\hline
\end{tabular}

From the evaluation above, LiBaBi exhibited the poorest performance from all the alloys, mainly due to bismuth. Additionally, the high amounts of polonium generated from bismuth alloys can be of concern due to its toxic and poisonous qualities [38-39]. With its high release fraction, it can easily travel and be ingested by the public. As a result of all this, bismuth-containing alloys will not be considered as potential candidates for the coolant/breeder. Although ${ }^{72} \mathrm{Ga}$ had a short life, it was still the major isotope that exhibited high decay heat, accident dose, and contact dose, respectively, and should be utilized with caution. In addition, ${ }^{60} \mathrm{Co}$, an activation product of zinc, can also be chemically toxic [40]. Although $\mathrm{LiSrPb}$ and $\mathrm{LiCuPb}$ were not closely examined in this study, they seemed to perform fairly well compared to other alloys specially those containing tin and zinc. Future work will take a closer look at the activation of strontium and copper.

\section{Conclusions}

The Lawrence Livermore National Laboratory is investigating the possibility to design lithium ternary alloys to replace lithium as blanket breeder/coolant of an IFE power plant that have similar breeding, corrosion, and thermal properties, but reduced chemical reactivity as compared to lithium. This study performed neutronic and activation analysis of numerous lithium ternary alloys in order to assess their performance in the LIFE blanket and guide the down selection process. The neutronic analysis determined energy multiplication factor and tritium breeding ratio. It 
was found that the best performing alloys (higher TBR and higher EMF) combine elements that exhibit low absorption cross section and high q-value such as $\mathrm{Sn}, \mathrm{Ba}, \mathrm{Sr}$, and $\mathrm{Zn}$, with elements with high neutron multiplying cross sections, like $\mathrm{Pb}$ and $\mathrm{Bi}$. A large number of alloys, especially with combinations formerly described, met TBR constrains of 1.05 and 1.1 and an EMF constrain of 1.1 for a wide range of lithium concentrations. When the EMF constraint was increased to 1.2, the demand to produce additional power was too high for most alloys except for those containing Sn. Additionally, it was found that when an alloy already contains a high amount of lithium (greater than 50\%), doubling the ${ }^{6} \mathrm{Li}$ content in lithium from $7.5 \%$ to $15 \%$ increases TBR by $13 \%$. After a certain percent of enriched ${ }^{6} \mathrm{Li}$, the lack of tritium and additional neutrons produced from ${ }^{7} \mathrm{Li}(\mathrm{n}, \mathrm{n}$ 'T) reactions ends up reducing the TBR. At lower total lithium concentrations $(<50 \%)$, the TBR will continue to increase to higher ${ }^{6} \mathrm{Li}$ enrichments since the ${ }^{7} \mathrm{Li}\left(\mathrm{n}, \mathrm{n}{ }^{\prime} \mathrm{T}\right)$ reactions will not be as significant.

Activation calculations were performed for a series of elements that exhibited good TBR and EMF properties. This analysis revealed bismuth as a poor choice; it had the highest numbers for all of the criteria evaluated. Alloys containing $\mathrm{Zn}$ and $\mathrm{Sn}$ also showed some of the highest decay heats, contact dose rates, and accident doses. Most of the alloys examined can be stored in dry containers at an estimated one year after shutdown. Additionally, after about 10 years, fractions of the volume of most blankets analyzed can be recycled at a time (after adequate cooling) without exceeding the remote handling limit. Accident doses were high in alloys containing $\mathrm{Zn}, \mathrm{Cu}$, or $\mathrm{Ga}$, but were not high enough to pose a major safety concern. With the exception of $\mathrm{LiBaBi}$, activation analysis demonstrated that all the alloys could be utilized as blankets of the IFE reactor without posing major environmental or safety concerns. A summary of the eight alloys that were closely looked at in this study is outlined in Table 5. From the neutronics point of view, it shows the minimum lithium atom concentrations that meet each of the three criteria. Furthermore, it outlines some requirements for each alloy to meet certain activation safety and environmental parameters. Overall, one can see that from these two perspectives the best alloys are $\mathrm{LiPbBa}, \mathrm{LiGaPb}, \mathrm{LiSrPb}$, and $\mathrm{LiPbZn}$. They have some of the lowest minimum lithium concentrations to meet the neutronics criteria, while obtaining the best values that meet the activation parameters.

Future work will look further to examine activation in additional alloys to see how the elements compare to those reviewed in this work. Possibility of lithium enrichment will also be considered.

Table 5. Summary of Ternary Alloy Neutronic and Activation Analysis Results

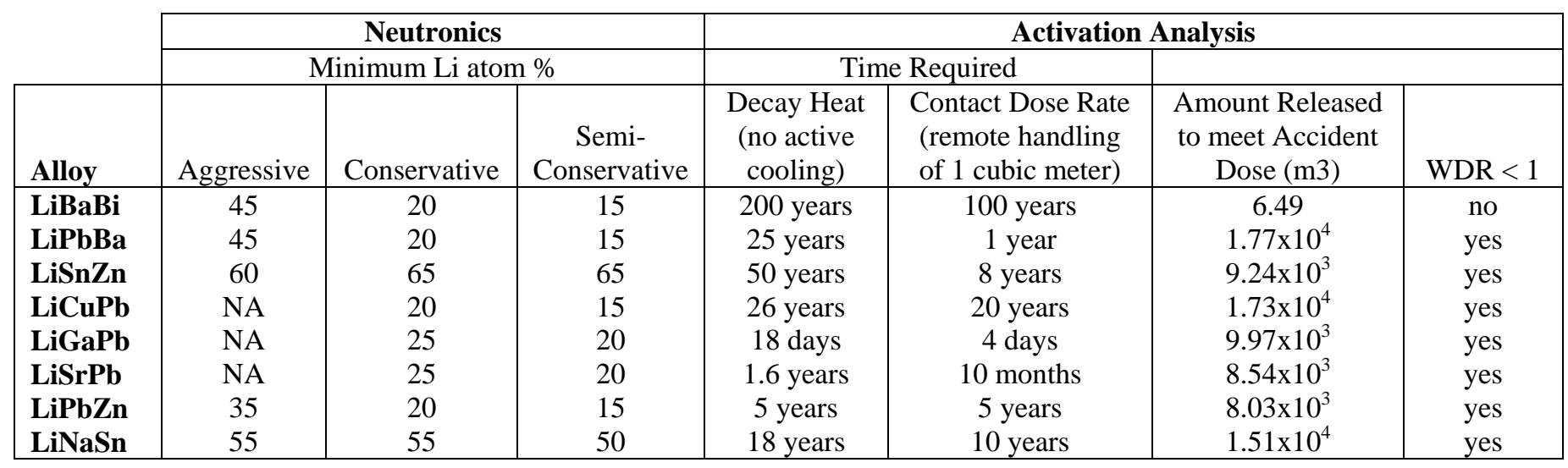

\section{Acknowledgements}

This work was support by LLNL LDRD Project 14-ERD-035. Portions of this work were performed under the auspices of the U.S. Department of Energy by Lawrence Livermore National Laboratory under Contract DE-AC5207NA27344.

\section{References}

[1] J. F. LATKOWSKI, et al., "Chamber Design for the Laser Inertial Fusion Energy (LIFE) Engine," Fusion Sci. Technol., 60, 54-60 (2011). 
[2] M.L. CORRADINI, D.W. JEPPSON. "Lithium Alloy Chemical Reactivity with Reactor Materials: Current State of Knowledge." Fusion Engineering and Design, 14.3-4, 273-88 (1991).

[3] T. IHILI, et al., "Review of Blanket Designs for Advanced Fusion Reactors." Fusion Engineering and Design, 83.7-9, 912-19 (2008).

[4] M.A. ABDOU, "Overview of Fusion Blanket R\&D in the US Over the Last Decade." Nuclear Engineering and Technology 37.5, 401-22 (2005).

[5] S. CHO et al., "Design and R\&D progress of Korean HCCR TBM," Fusion Engineering and Design, 89,1137 (2014).

[6] S. CHO et al., "Overview of Helium Cooled Ceramic Reflector Test Blanket Module Development in Korea," Fusion Engineering and Design, 88, 621 (2013).

[7] K.M. FENG et al., "New progress on design and R\&D for solid breeder test blanket module in China," Fusion Engineering and Design," in press (2014).

[8] E.R. KUMAR, et al., "Preliminary design of Indian Test Blanket Module for ITER," Fusion Engineering and Design 83, 1169-1172 (2008).

[9] M. ENOEDA et al., "Development of the Water Cooled Ceramic Breeder Test Blanket Module in Japan," Fusion Engineering and Design, 87, 1363 (2012).

[10] T.K. GIL, M.S. KAZIMI, “The Kinetics of Liquid Lithium Reaction with Oxygen/Nitrogen Mixtures," MIT PFC/RR-83-1 (1986).

[11] L.V. BOCCACCINI, et al., "Present status of the conceptual design of the EU Test Blanket Systems, Fusion Engineering and Design (2011),

[12] N.B. MORLEY, et al., "Recent Research and Development for the Dual-Coolant Blanket Concept in the US," Fusion Engineering and Design, 83, 920-927 (2008).

[13] Y. WU, FDS Team, "Design analysis of the China dual-functional lithium lead (DFLL) test blanket module in ITER," Fusion Engineering and Design, 82(15), 1893-1903 (2007).

[14] Y. WU, FDS Team, "Design status and development strategy of China liquid lithium-lead blankets and related material technology," Journal of Nuclear Materials, 367, 1410-1415 (2007).

[15] D.W. LEE, et al., "Preliminary design of a helium cooled molten lithium test blanket module for the ITER in Korea," Fusion Engineering and Design, 82, 381-388 (2007).

[16] M. ABDOU, et al., "Blanket/first wall challenges and required R\&D on the pathway to DEMO," Fusion Engineering and Design, 100, 2-43 (2015).

[17] E. I. MOSES, "The National Ignition Facility and the Promise of Inertial Fusion Energy," Fusion Sci. Technol., 60, 11-16 (2011).

[18] M. DUNNE, et al., "Timely Delivery of Laser Inertial Fusion Energy (LIFE),” Fusion Sci. Technol., 60, 19-27 (2011).

[19] L.A. EL-GUEBALY, S. MALANG. “Toward the Ultimate Goal of Tritium Self-sufficiency: Technical Issues and Requirements Imposed on ARIES Advanced Power Plants." Fusion Engineering and Design, 84, 2072-83 (2009).

[20] W.R. MEIER, E.C. MORSE. "Blanket Optimization Studies for the HYLIFE Inertial Confinement Fusion Reactor.” Fusion Technology, 8, 2681-95 (1985). 
[21] R. SACKS, et al., "Parameter Study of an Inertial Fusion Energy Chamber Response Using the 1-D Bucky Radiation Hydrodynamics Code." Fusion Sci Technol., 66, 349-57 (2014).

[22] W.R. MEIER, “Fusion Power Multiplication for LIFE,” LLNL Report LLNL-MI-666819 (Feb. 3, 2015).

[23] T. GOORLEY et al., “'Initial MCNP6 Release Overview,” Nucl. Technol., 180, 3, 298 (2012); http://dx.doi.org/10.13182/NT11-135.

[24] M.B. CHADWICK, et al., ENDF/B-VII.0: Next Generation Evaluated Nuclear Data Library for Nuclear Science and Technology. Nuclear Data Sheets, 1072006 2931-3060.

[25] W. MEIER, P. Amendt, Personal communication, 2014.

[26] S. REYES, et al., "Life Tritium Processing: A Sustainable Solution for Closing the Fusion Fuel Cycle." Fusion Sci. Technol., 64, 187-93 (2013).

[27] J. SANZ, O. CABELLOS, N. GARCIA-HERRANZ. “ACAB. Inventory Code for Nuclear Applications: User's Manual V.2008.” Madrid, Spain (2008).

[28] R.A. FORREST, The European Activation System: EASY-2007 Overview, UKAEA FUS 533, 2007

[29] J.P. CATALAN, F. OGANDO, J. SANZ, “Activation Analysis for a He/LiPb Dual Coolant Blanket for DEMO Reactor," Fusion Sci. Technol., 60, 438-442 (2011).

[30] S D.A. PETTI, et al., "Re-evaluation of the Use of Low Activation Materials in Waste Management Strategies for Fusion," Fusion Engineering and Design, 51-52, $435-444$ (2000).

[31] S.J. PIET, E.T. CHENG, and S. HERRING, "Initial Integration of Accident Safety Waste Management, Recycling, Effluent, and Maintenance Considerations for Low-Activation Materials," Fusion Technology, 19, 14661 (1989).

[32] J.F. LATKOWSKI, J. SANZ, S. REYES, J. GOMZ DEL RIO, "Selection of IFE Target Materials from a Safety and Environmental Perspective," Nuclear Instruments and Methods in Physics Research, A 464, 422-427 (2001).

[33] D. LAYCAK, "Preliminary Study of Radiological Doses from Released Nuclides from LIFE Reactor," LLNL Safety Division, May 2012.

[34] S.J. PIET, E.T. CHENG, and L.J. PORTER, "Accident Safety Comparison of Elements to Define LowActivation Materials," Fusion Technology, 17, 636-57 (1990).

[35] P.E TURCHI, "Thermodynamic Assessment of the Ternary Alloy System Li-Sn-Zn, " LLNL report LLNLTR-653675, April 2014.

[36] A. JOLODOSKY, M. FRATONI, "Neutronics Evaluation of Lithium-Based Ternary Alloys in IFE Blankets," LLNL-SR-677422 (2015), www.osti.gov/scitech/biblio/1223840

[37] S. MALANG, R. MATTAS. "Comparison of Lithium and Eutectic Lead-lithium Alloy, Two Candidate Liquid Metal Breeder Materials for Self-Cooled Blankets.” Fusion Engineering and Design, 27, 399-406 (1995).

[38] J. HARRISON, et al., "Polonium-210 as a Poison." Journal of Radiological Protection, 27, 17-40 (2007).

[39] G.I. KHORASANOV, A.P. Ivanov, and A.I. Blokhin. "Polonium Issue in Fast Reactor Lead Coolants and One of the Ways of Its Solution." Proceedings from ICONE10 $10^{\text {th }}$ International Conference on Nuclear Engineering. (2002). 
[40] L. R. PAYNE. “The Hazards of Cobalt.” Occupational Medicine, 27, 20-25 (1977). 